\title{
WFUMB position paper. Incidental findings of the salivary glands
}

\author{
Ewa J Bialek', Adrian Lim², Yi Dong³, Daniela Fodor4, Norbert Gritzmann", \\ Christoph F Dietrich ${ }^{6}$
}

${ }^{1}$ Department of Diagnostic Ultrasound and Mammography, Mazovian Bródnowski Hospital, Warsaw, Poland, ${ }^{2}$ Imaging Department, Imperial College Healthcare NHS Trust, Charing Cross Hospital, Fulham, UK, ${ }^{3}$ Department of Ultrasound, Zhongshan Hospital, Fudan University, China, ${ }^{4} 2^{\text {nd }}$ Internal Medicine Department, "Iuliu Hatieganu" University of Medicine and Pharmacy, Cluj-Napoca, Romania, ${ }^{5}$ SONOSEMINARE, Vienna, Austria, ${ }^{6}$ Department Allgemeine Innere Medizin (DAIM) Kliniken Hirslanden Beau Site, Salem und Permanence, Bern, Switzerland

\begin{abstract}
A salivary incidentaloma (SI) stands for any focal salivary lesion, independent of size, discovered by any imaging method including ultrasonography (US), computed tomography (CT), magnetic resonance imaging (MRI), multimodal positron emission tomography (PET) combined with CT or MRI, or X-ray imaging, performed for another reason, in the absence of known salivary glands' disease. The article presents a detailed analysis of salivary gland diseases with the emphasis on neoplasms. It describes frequency of SIs found on imaging, their prevalence, epidemiology and clinical significance. The probability of malignancy or malignant transformation of a SI, its imaging features, recommended treatment, management and follow-up, as well as ethical issues, psychological burden, informed decision making, economical consequences and costs are discussed. The general prevalence of SIs is low, but is dramatically increasing over time, and may rise significantly in selected groups of oncologic patients. SIs most frequently turn out to be benign primary neoplasms or pseudotumors, including intraparenchymal lymph nodes. SIs detected by other imaging methods should be subsequently assessed with US. Solid SIs demand ultrasound guided fine-needle aspiration cytology (US-FNAC). Neoplasms should undergo surgery. Post-operative US follow-up is mandatory for malignant tumors and recommended for benign neoplasms.
\end{abstract}

Keywords: salivary gland; incidenaloma; guideline; neoplasia; inflammation

\section{Introduction and definition}

The World Federation for Ultrasound in Medicine and Biology (WFUMB) is dedicated to the advancement of ultrasound (US) by encouraging research, promoting international cooperation, disseminating scientific information and improving communication and understanding in the world community using ultrasound in medicine and biology [1]. WFUMB is addressing the issue of in-

Received 10.03.2021 Accepted 14.04.2021

Med Ultrason

2021, Vol. 23, No 3, 329-338

Corresponding author: Prof. Dr. med. Christoph F. Dietrich, MBA

Department of Internal Medicine (DAIM)

Kliniken Hirslanden Bern, Beau Site,

Salem and Permanence

Schänzlihalde 11, 3031 Bern, Switzerland

E-mail: c.f.dietrich@googlemail.com cidental findings with a series of publications "Incidental imaging findings - the role of medical ultrasound" [1]. So far adrenal gland IF have been described in detail [2].

The definition of a salivary incidentaloma (SI) encompasses any focal salivary lesion, independent of size, discovered by any imaging method including ultrasound (US), computed tomography (CT), magnetic resonance imaging (MRI), multimodal positron emission tomography (PET) combined with CT or MRI, or X-ray imaging, performed for other reason, in the absence of known salivary glands' disease [1].

Major salivary glands are symmetrically located in the head and neck and include the parotid gland, submandibular salivary gland and sublingual salivary gland. Accessory parotid glands may be located in the cheek along the Stenon duct, the excretory duct of a parotid gland. Apart from them, there are hundreds of minor salivary glands, which are not apparent on conventional imaging, 


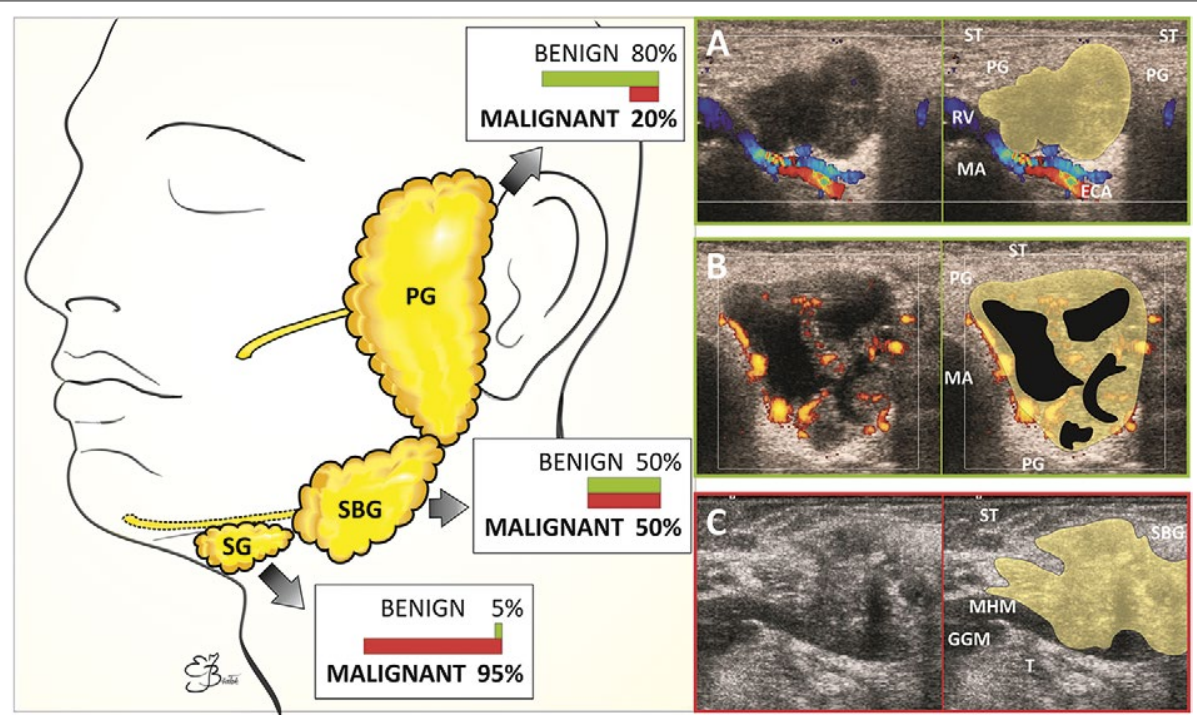

Fig 1. Morphology in relation to frequency of benign and malignant salivary gland tumours. The scheme of major salivary glands with images representing most common neoplasms (A-C) (tumors shadowed on yellow). Percentages for the ratios of benign to malignant salivary gland neoplasms according to Bradley [5]. A - pleomorphic adenoma. B - Warthin tumor. C - adenoid cystic cancer. ECA - external carotid artery; GGM - genioglossus muscle; MA - acoustic shadow behind the mandible bone; MHM - mylohyoid muscle; PG - parotid gland; RV - retromandibular vein; SBG - submandibular salivary gland; SG - sublingual salivary gland; $\mathrm{ST}$ - subcutaneous tissue; $\mathrm{T}$ - tongue.

in the submucosa of digestive and respiratory tracts. Salivary gland tissue may be also heterotopically located in different neck structures.

Most common diseases of salivary glands are inflammation and sialolithiasis [3]. They often coexist and nearly always cause symptoms. The incidence rates of salivary tumours appear to be low, but reliable data are difficult to obtain and vary depending on the study due to a lack of studies screening large populations, due to changing histopathological classifications (newest one WHO classification dates from 2017 [(4)]), probable differential incidence rates between different populations, and improvement of imaging methods, which increases detection rates.

Estimates of salivary gland neoplasms incidence rate range from 0.4 to 13.5 per 100,000 population [5]. Most of the salivary gland neoplasms are benign (e.g., 86\%) [6]. Malignant epithelial salivary gland neoplasms constitute only about $3-6 \%$ of all head and neck malignancies [5].

Salivary gland neoplasms are mainly primary and have epithelial origin. Mesenchymal (nonepithelial) neoplasms make up only $1.9-5 \%$ of all major salivary gland neoplasms [7]. Lymphomas are rarely found, are mostly non-Hodgkin and mainly due to systemic involvement, seldom as primary disease [8]. Metastases are less common, accounting for about $1 \%(108 / 10,944)$ of cases according to Seifert et al [9] and occur in the parenchyma or within intraparenchymal lymph nodes of the parotid or submandibular salivary glands. The origin of metastases to salivary glands is usually from within the head and neck particularly the cutaneous malignancies squamous cell carcinoma and melanoma $[9,10]$. However, depending on geographic location, metastases may be found prevailing over primary parotid neoplasms, like in Australia, reaching $75 \%(178 / 232)$ of the patient cohort [10], which is connected with regional elevated incidence of skin cancers. Additionally, there are reports showing a rising incidence of metastases to parotid glands over recent decades in other countries such as Germany [11]. Most often (61-87\%) the neoplasms occur in the partoid [6,12-14], less commonly in the submandibular salivary gland $(9.5-11 \%)$ and minor salivary glands $(9-28.5 \%)$ and least commonly in the sublingual salivary gland (0.5$1 \%)[6,12,14]$. The ratios of 100:10:1:10 for site distribution of salivary gland neoplasms between parotid, submandibular, sublingual and minor salivary glands were suggested by Willis in 1953 [15] and confirmed in subsequent studies [5]. The trend of increasing frequency of tumor malignancy is inverse to the salivary glands size. The lowest rate of malignancy (9-32\%) is noted in largest parotid glands, in which tumors are most commonly encountered, followed by submandibular salivary gland $(25-43 \%)$ and minor salivary glands (40-62\%), and up to $75-100 \%$ in sublingual salivary glands, which are fortunately the rarest sites of neoplastic growth $[6,12,14,16]$. Bradley [5] suggested percentages for the ratios of benign to malignant salivary gland neoplasms are $80 \%$ vs. 


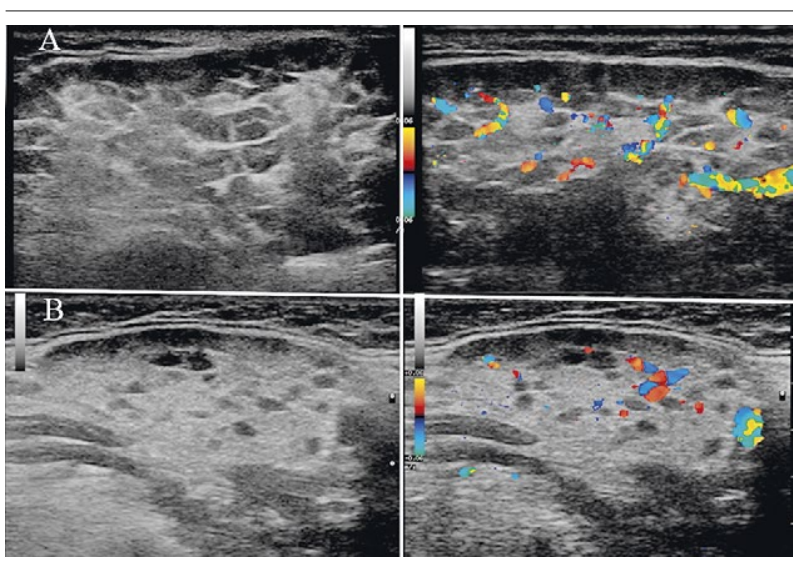

Fig 2. Gray scale and colour Doppler of the parotide gland (A) and submandibular gland (B) in a patient with Sjögren syndrome. Note the hypoechoic diffuse nodular lesions, hyperechoic fibros septa and increased vascularity (especially in parotid gland).

$20 \%$ for parotid gland, $50 \%$ vs. $50 \%$ for submandibular salivary gland, $5 \%$ vs. $95 \%$ for sublingual salivary glands and $20 \%$ vs. $80 \%$ for minor salivary glands (fig 1 ). Therefore, lesions in submandibular salivary glands should be regarded as highly suspicious for malignancy and even more so in the sublingual salivary glands.

Pleomorphic adenomas (mixed tumours) and Warthin tumors (cystadenolymphomas) are the main benign neoplasms, constituting 93\% $[6,13,17]$. The malignant salivary neoplasms are most commonly mucoepidermoid carcinoma, adenoid cystic carcinoma and adenocarcinoma not otherwise specified (NOS) accounting for about $65 \%$ of cases $[6,14,17]$. Salivary tumors may be multiple, of the same origin or of different type - most often Warthin tumor, occurring either synchronously or metachronously in the same salivary gland or in different ones [17]. Carcinomas of the major salivary glands are a heterogeneous group of neoplasms, ranging from low grade to aggressive malignancies, with etiologic and biological variability showing varying prevalence according to age, gender, race, and geographic location even within the same country [14,17-19].

Chronic inflammatory diseases may also present themselves as solid lesions, single or multiple. This includes granulomatous diseases such as tuberculosis or sarcoidosis and chronic sclerosing sialadenitis (Küttner tumor) [3]. Sjögren Syndrome, an autoimmune disease, may present as scattered multiple small, oval areas disseminated in both parotid and submandibular salivary glands [3] (fig 2).

Lack of high quality large prospective trials makes it difficult to define reliable evidence-based guidelines concerning the management of salivary gland incidental findings.

\section{Chances of detecting SIs}

Reports relating to SIs on CT or MRI are scarce. Parotid gland masses were incidentally detected in $2.5 \%$ $(5 / 225)$ of patients undergoing CT cranial angiography [20]. On MRI (1.5T) SIs were reported only in $0.26 \%$ $(2 / 700)$ of patients at the age of 73 years [21] and in $0.27 \%(2 / 730)$ of patients who underwent imaging of the temporomandibular joint [22]. More data is available concerning SIs on PET/CT. The frequency of incidental findings on 18F-fluorodeoxyglucose (FDG) PET/CT scans showing $18 \mathrm{~F}-\mathrm{FDG}$ uptake in parotid glands ranged from $0.4 \%$ to $1.73 \%$ [23-25]. Only $4 \%$ of focal parotid incidental uptake (FPIU) turned out to be malignant in the study group of Makis et al [24] and 9.6\% in the metaanalysis of Treglia et al [26]. However, Ustun et al [25] reported an incidence of parotid metastases amounting to $36.4 \%$ and similarly high values of $45 \%$ were reported by Mabray et al [27], where FPIU was frequently a manifestation of the patient's known malignancy (metastasis or lymphoma). It has to be noted that the high malignancy rates in incidental masses detected on multimodal PET imaging are mostly due to the fact that PET/CTs are performed mostly in oncologic patients, with high probability of metastases. Britt et al [28] performed a retrospective review of 771 patients who underwent parotidectomy. Within the group of parotid masses found incidentally on CT, MRI or PET/CT, carried out for an unrelated indication, the overall rate of malignant neoplasms was $6 \%(4 / 67)$. In the group where masses were identified in symptomatic patients owing to pain, facial nerve dysfunction, palpable mass or other reasons, the frequency of malignant neoplasm was higher, 32.7\% (230/704) [28].

A dramatic increase in the prevalence of parotid incidentalomas (PIs) over time detected on imaging was identified by Britt et al [28]. Their study reports a $155 \%$ increase over a 20-year study period (1994-2013), where $4 \%$ of all parotoidectomies were performed for PIs during the first decade and $10.2 \%$ during the second decade.

The percentage of PIs that were malignant, detected by various imaging methods, was $5 \%(95 \% \mathrm{CI} 2,10)$ [29]. The histology of the SIs found on CT, MRI, PET/ CT or PET/MRI should be confirmed using fine-needle aspiration cytology or core biopsy guided by US [30,31].

On US, SIs may also be detected during scans performed for thyroid, lymph nodes or carotid arteries asessment. Salivary glands screened by Onda et al during thyroid US revealed abnormal incidental findings in about $4 \%$ of patients (36/908). This included atrophy/swelling, unclear boundaries of the gland or hypervascularity in addition to internal heterogeneity, as well as tumors [32]. Tumors underwent fine needle aspiration cytology 


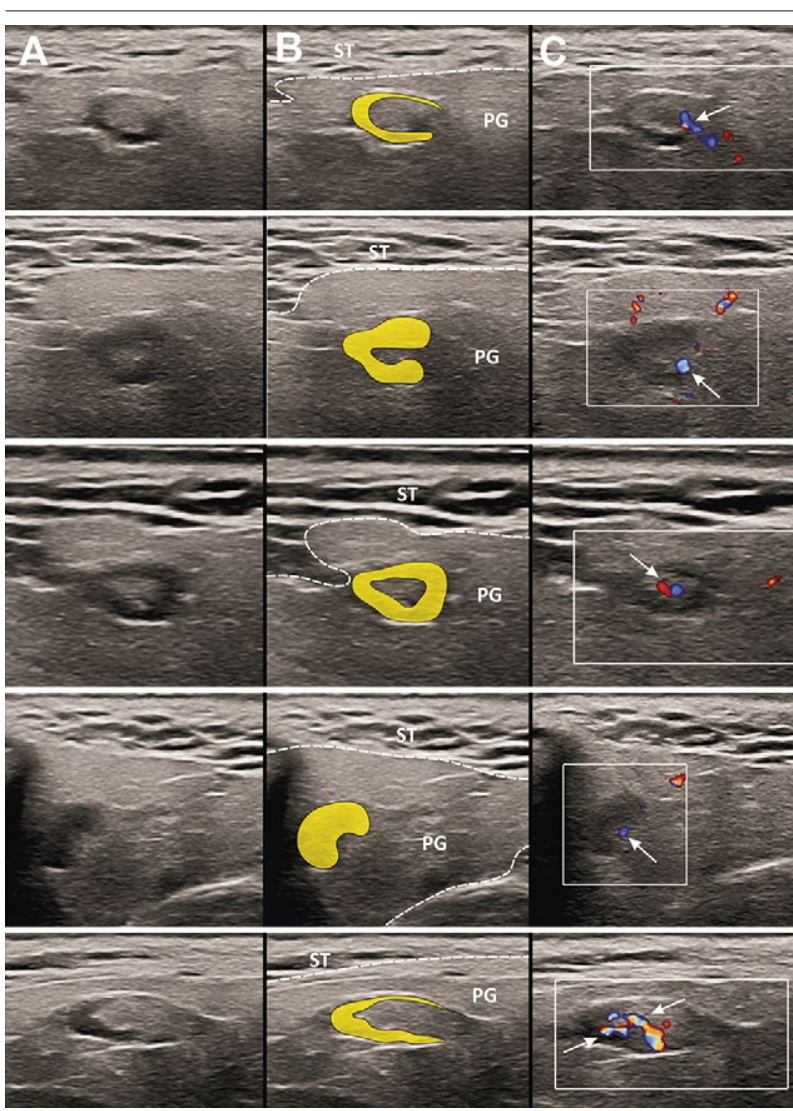

Fig 3. Normal intraparenchymal lymph nodes in the parotid gland, which should not be mistaken for a pathologic lesion: A) raw gray-scale images; B) lymph nodes parenchyma marked with yellow; border of the parotid gland marked with a dashed line; PG - parotid gland; ST - subcutaneous tissue; C) color Doppler images showing hilar or central branching lymph node vessels - arrows.

(FNAC), while other abnormalities were evaluated with further blood tests and imaging studies [32].

Specific categories of incidental findings in salivary glands are typically calcification or stones/sialoliths [33]. Calcifications were reported in parotid glands in $4 \%$ of noncontrast head CT and revealed association with HIV, alcoholism, chronic kidney disease, autoimmune disease and elevated alkaline phosphatase [34]. From 350 incidental findings identified in 999 cone-beam CT of the head and neck, submandibular gland stones constituted $0.8 \%$ [35]. Incidental reports have also been reported from the sublingual gland revealing multiple sialoliths on orthopantomograms [36]. In cases of salivary glands calcification/stones detected by an imaging method which does not provide visualization of the gland parenchyma and excretory ducts, US should be taken in consideration as it permits differentiation between true stones, phleboliths or tumor calcification. A stone may also be incidentally discovered on US performed for other reasons. In the Sigismund et al study, US allowed for detection of stones not causing symptoms in $2.6 \%(61 / 2,322)$ of patients with sialolithiasis [33].

It is important not to mistake intraparenchymal lymph nodes, which are intrinsic structures especially in parotid glands parenchyma, from true focal abnormalities. This may be challenging, especially for inexperienced sonographers (fig 3) and in indeterminate cases, US-FNAC should be performed.

In summary, allowing for the difference amongst all the reported studies, the prevalence of SIs on imaging ranges from $0.26 \%$ to about $10 \%$, with the rate of malignancy of $4 \%$ rising to $45 \%$ in SIs detected on FDG PET/ CT studies. One should be aware that these studies having PET/CT will be a highly selected group of patients, likely with known malignancy.

\section{Salivary gland neoplasm}

\section{Prevalence, epidemiology}

The etiology of salivary gland neoplasm in most patients is unknown [37] but their occurence is associated with high and low-dose irradiation, explosion to silica dust, nickel, rubber manufacturing, using kerosene as a cooking fuel, high serum cholesterol, low vitamin intake and low intake of dark yellow vegetables [38]. In Epstein-Barr virus infections, a higher incidence of undifferentiated carcinoma, Warthin's tumor and salivary T-cell lymphoma was reported in AIDS patients [38]. Warthin tumors are strongly associated with smoking [38]. Recent studies revealed specific chromosomal abnormalities and gene mutations connected with benign and malignant salivary neoplasms [38]. It is hoped that these genetic markers may in future be useful in salivary glands' neoplasms diagnosis, therapy and prognosis [38,39].

\section{Clinical significance}

Clinical significance of SIs depends on the method of their detection. The most significant lesions seem to be tumors detected on multimodal PET imaging showing FDG uptake but these examinations were typically performed in patients with a known malignancy for staging [27]. SIs detected by other imaging modalities are most likely benign primary neoplasms or pseudotumors, including intraparenchymal lymph nodes.

\section{Salivary glands and their incidentalomas}

Two of the most common benign salivary gland neoplasms may undergo malignant transformation.

Pleomorphic adenomas (PA), are the most common neoplasms of salivary glands and may undergo malignant transformation to carcinoma in about $0.15-2.86 \%$ of new cases, or in 3.2-3.3\% of recurrent cases (as re- 


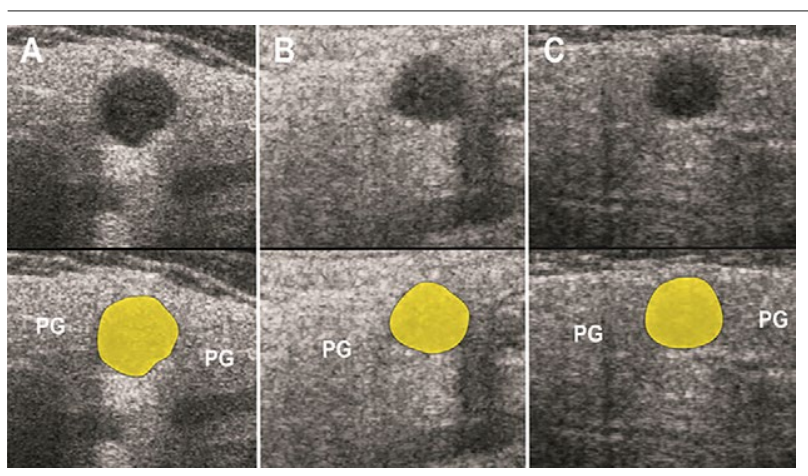

Fig 4. These lesions all have similar grey-scale ultrasound appearances but are of different aetiologies: A) small pleomorphic adenoma; B) small mucoepidermoid cancer; C) Small reactive lymph node without apparent hilum. All presented masses demand further work-up by means of US-guided FNAC.

ported Valstar et al from analysis of 3.506 cases of PA from Dutch pathology registry [40] and Andreasen et al from analysis of 5.497 patients from The Danish Pathology Data Bank [41]. Recurrence of PA are usually multifocal and encountered in about $6.7 \%$, especially after incomplete resection of a PA, with a median time to first recurrence of 7 years [40]. The rate of re-recurrence of PA may reach $46.6 \%$, posing a significant problem for these patients [41]. Warthin tumors may undergo malignant transformation much less often than PAs, in about $0.5 \%$ of cases [42]. However, in a retrospective histological evaluation by Alnoor et al the prevalence rate of lymphoid neoplasia in Warthin tumors was found higher, $3.4 \%$ : with overt lymphoma in $2.2 \%$, and in situ follicular neoplasia of $1.1 \%$ [43]. An interesting issue is the possibility of high-grade transformation within salivary gland carcinoma, usually previously low grade, which implies increased aggressiveness and poorer prognosis. The concept has been introduced in the latest 4th edition of WHO classification of tumors [4].

\section{Imaging features including echo texture}

Low-grade salivary malignancies may show slow growth and no typical malignant features, mimicking benign tumors [3], especially when less than $20 \mathrm{~mm}$ in size (fig 4). Some small metastases may show pseudo-benign imaging features. This poses a serious pitfall for imaging specialists where accurate differentiation of benign from malignant salivary lesions in conventional imaging is usually not possible.

Obviously, in case of aggressive or high-grade tumors irregular shape, spiculated or ill-defined margins, infiltration of surrounding tissues, inhomogeneous structure and the presence of abnormal lymph nodes malignancy is likely $[3,19,44]$ (fig 1 , fig 5). Nevertheless, the lack of above mentioned imaging features does not completely exclude malignancy. In the study by Borsetto et al only $33.3 \%$ of all confirmed malignant tumors had characteristic imaging features of malignancy [45]. The most commonly occurring benign salivary neoplasms, pleomorphic adenoma and Warthin tumors, have a few typical but not pathognomic imaging features. Pleomorphic adenomas (PAs) often have lobulated, polycyclic margins and may be inhomogeneous $[3,46]$, which reflects their complex histopathological nature, with epithelial and myoepithelial cells arranged in mucoid, myxoid or chondroid background, sometimes with osseous metaplasia or lipomatous differentiation [47] (fig 1, fig 6). PAs are usually poorly vascularized but have varying vascular density $[3,46]$. Polycyclic shape is a poor discrimantor of benign and malignant salivary neoplasms, where either may present with any shape [3]. In Warthin tumors (WTs) anechoic spaces reflecting their histopathological composition are often encountered (up to $93 \%$ by Shimizu et al) [48]. The stroma of a WT is composed of dense lymphoid tissue with cystic areas lined by a bilayered epithelium, which may present papillae [47]. However,

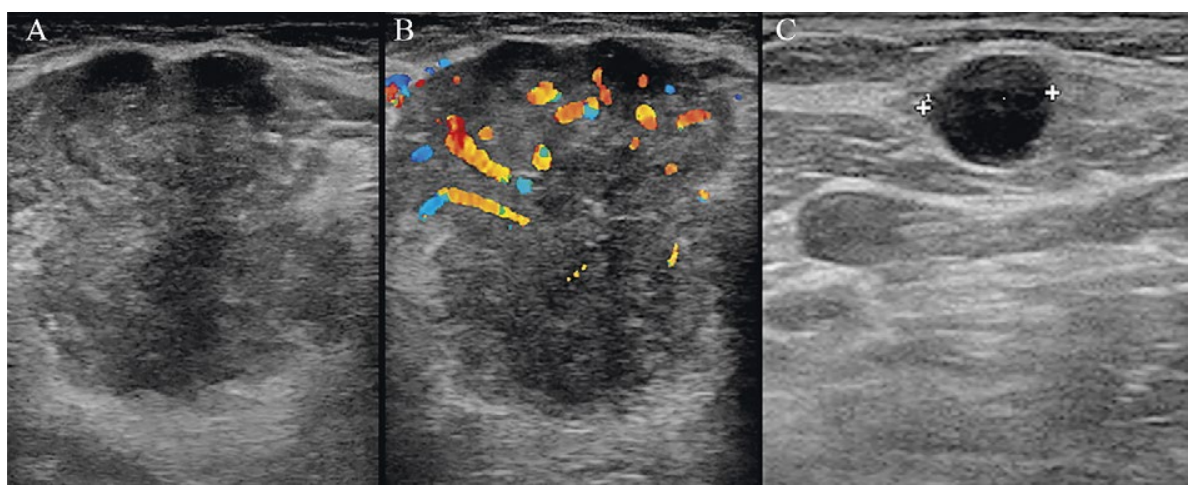

Fig 5. Mucoepidermoid carcinoma of the parotid gland, grey scale (A) and Color Doppler (B) (irregular shape, ill defined margins, inhomogenous apparence and hypervascularized tumor) associated with round, hyopechoic and without hillum regional metastatic lymphnode (C). 


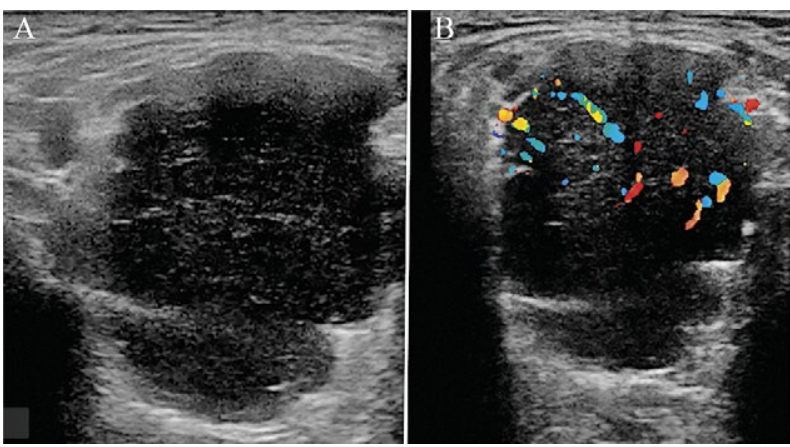

Fig 6. Pleomorphic adenoma, grey scale (A) and color Doppler (B) with lobulated, polycyclic margins, slighly inhomogeneous and moderate vascularised

other benign and malignant salivary neoplasms may also present with internal fluid-like components [46,49]. Most WTs are very well vascularized [3] (fig 7).

\section{US contrast agents and elastography}

Relatively newer US techniques include ultrasound contrast agents and elastography. Neither of them has been revolutionary in characterising salivary gland neoplasms. Application of microbubble contrast allows for additional assessment of microvasculature of tumors and contrast kinetics, but present studies are limited in number and are based on insufficiently large and selected populations of patients, which does not allow for drawing far-reaching conclusions [50]. According to Bhatia et al, elastography appears suboptimal for detection of malignancy in the salivary glands because of overlapping elestic properties between benign and malignant lesions [51]. Similar conclusions are drawn from a meta-analysis concerning parotid lesions, showing heterogenous study results and indicating a limited value of elastography in differential diagnosis between malignant and benign tumors, which may be due to their histopathological variety [52]. However, higher stiffness in shear wave elastography (SWE) may indicate a parotid lymphoma in primary Sjögren Syndrome, promising the potential use of SWE for early diagnosis, biopsy guidance and possibly treatment monitoring [53].

\section{Contrast-enhanced and nuclear medicine}

\section{techniques}

Like US, conventional CT and MRI even with additional post-contrast imaging does not allow for a reliable differentiation between malignant and benign salivary neoplasms because of a significant overlap in morphological features between the two groups. Moreover, these two latter techniques are much more expensive, may have contraindications, are less quickly available, CT utilizes ionizing radiation and CT/MRI contrasts have potential side-effects. Irregular margins and invasion of local structures on $\mathrm{CT} / \mathrm{MRI}$ detected lesions, similar

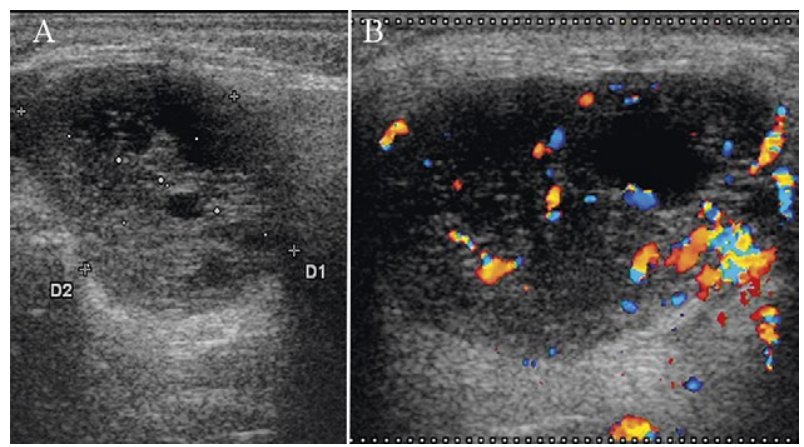

Fig 7. Warthin tumour, grey scale (A) and colour Doppler (B): inhomogenous structure, with fluid component (cystic areas) and hypervascularisation (courtesy Dr Manuela Lenghel)

to US, suggests malignancy $[19,44]$. However, these features may not be present, especially in lower-grade or smaller sized malignancies. On MRI, an additional feature suggesting malignancy is hypointensity on T2weighted images $[19,44]$. Newer MRI sequences bring additional values and can improve diagnostic accuracy, however do not allow for definite detection of tumor malignancy and are time consuming. High diffusion restriction on diffusion-weighted-imaging (DWI) corresponding with its derived low apparent diffusion coefficient (ADC) values and high intratumoral susceptibility signal intensity (ITSS) on susceptibility-weighted imaging (SWI), the latter an indirect indicator of angiogenesis, may indicate malignancy [54]. However, Warthin tumors may have confusing features, showing even higher diffusion restriction than malignant tumors and similar ITSS [54]. Low and progressive wash-in on dynamic contrastenhanced perfusion-weighted imaging (DCE-PwI) in association with high ADC values were observed only in benign neoplasms [55]. But Warthin tumors ADC values and contrast enhancement curve patterns overlapped with lymphomas and malignant tumors [55]. Recently introduced amide proton transfer-weighted (APTw) MRI can be useful in discriminating malignant from benign tumors of the major salivary glands, where APTw-signals in malignant tumors are significantly higher than in benign ones [56]. However, this needs confirmation in further multicentre studies. It is not possible to differentiate benign from malignant salivary gland tumors based on 18F-FDG PET/CT, as benign neoplasms may show FDG uptake [24]. An interesting fact is the specific character of Warthin tumors, which are commonly hot on $99 \mathrm{mTc}$ scintigraphy unlike the majority of other benign and malignant salivary neoplasms [57]. This may be used as an adjunct to the decision making process when suspected Warthin tumorss are managed conservatively with clinical observation in patients who have significant comorbidities, refuse surgery or are of advanced age [58]. 


\section{Combined imaging criteria}

In cases of sizable salivary lesions or tumors in the deep parotid lobe or in case of malignant tumor, where there is a need for assessment of the deep lying lymph nodes (e.g. at the base of the skull, retropharyngeal, retrotracheal), inaccessible by US, preoperative MR or CT is indicated to determine patient management or for surgical planning [19]. In case of advanced and high-grade malignant tumors, a staging chest $\mathrm{CT}$ is recommended [19]. Kikuchi et al suggested that the diagnostic algorithm of parotid tumors begin with DWI MRI in order to exclude pleomorphic adenomas based on high ADC values, with subsequent $99 \mathrm{mTc}$ scintigraphy to exclude Warthin tumors, leaving core needle biopsy (CNB) to be performed in the remaining cases [57]. However, such an algorithm appears far more expensive than US-FNAC and US follow-up.

\section{Image (US) - guided biopsy}

The procedure of cell sampling for cytology assessment by aspiration with use of a needle is described using two interchangeable terms: fine needle aspiration biopsy (FNAB) and fine needle aspiration cytology (FNAC). Recommendations, including those issued by The Education Committee of The American Head and Neck Society (AHNS) within the series "Do you know your guidelines", United Kingdom National Multidisciplinary Guidelines and The National Comprehensive Cancer Network (NCCN) Guidelines, advocate US guided FNAC (US-FNAC) as a standard first-line procedure for all salivary tumors $[19,59,60]$, whether solid or cystic [49]. USFNAC is simple in technique, almost painless, with rare complications, fast, minimally invasive, easily available and is cost-effective. The of accuracy FNAB will vary depending on the experience of the center expressed by the amount of examined and treated patients, sampling methods, the person who is performing the procedure: a pathologist, a radiologist or a clinician, and they are better when FNAB is monitored with US $[61,62]$.

To improve accuracy, FNAC is best performed at a high-volume case load center [63] and reported by an expert histopathologist [59]. The Education Committee of the AHNS grants permission to perform FNAB without US guidance if the lesion is easily accessed anatomically or palpable [19], however, US guidance is advisable where available. The drawback of FNAC is its moderate to low sensitivity, with varied reported percentages, $78 \%$; with $95 \%$ CI $74 \%, 82 \%$ ( $\mathrm{n}=5647$ patients) [61], as low as $58-59 \%(n=371$ FNAC; $n=554$ FNAC) $[64,65]$ or as high as $82 \%$ ( $\mathrm{n}=996$ patients) [66]. One of the reasons, as with imaging, are the intrinsic properties of low-grade malignancies, with no significant cell atypia possible to be recognized basing only on their morphology [64]. The specificity and negative predictive value (NPV) of FNAC in differentiating malignant from benign salivary lesions is high, but with large diversity in reported percentages [61]. In a meta-analysis of 5647 patients, specificity was 98\% (95\% CI 97\%, 98\%) [61] and other studies have cited 99\% [64]. NPV for determining parotid malignancy was reported ranging between 91 and 95\% [63-65,67]. False negative results are unfortunately possible in FNAC; therefore, patients with results negative for malignancy should be monitored with US. In case of rapid enlargement or suspicious US features, US-FNAC should be repeated. Core needle biopsy $(\mathrm{CNB})$ is reported to have better sensitivity than FNAB, reaching 88.2-89.6\% $[64,68]$. Nevertheless, CNB requires local anesthesia, is regarded more invasive and potentially exposes the patient for the risk of facial nerve injury, seeding of tumor cells, hematoma or inflammation, therefore it should be limited to cases where the definite diagnosis is not possible with FNAC or when lymphoma is suspected $[69,70]$.

\section{Follow-up}

There are no established guidelines for the followup post-treatment of malignant salivary neoplasms. The Committee of the AHNS [19] suggests individual adjustment of the scheme of monitoring and present conventional schedule with repeated clinical examinations and history ("every 1-3 months in the first year, every 2-6 months in the second year, every 4-8 months up to five years and later each year") and imaging after 3 months with the same modality as before treatment. Special attention is advocated for adenoid cystic carcinoma where regular neck imaging and consideration of annual chest $\mathrm{CT}$ to enable early detection of recurrence or metastases [19]. We recommend regular US-follow up post resection of not only malignant, but also of benign, salivary neoplasms. The latter, for example, in pleomorphic adenomas frequently recur and in the case of Warthin tumors, there is possible metachronous appearance.

\section{Surgery and other treatment options}

The general first-line treatment option for primary salivary neoplasms is surgery [19,59] apart from lymphomas, which are treated with chemotherapy [71]. For submandibular salivary glands, total excision of the gland is performed, while for parotid glands, the extent of surgery depends on the size, location and the nature of the tumor. This may include extracapsular dissection, partial superficial parotidectomy and superficial parotidectomy $[45,72]$. Elective neck lymph nodes dissection is considered for all malignant tumors but is mandatory for high-grade and high-stage neoplasms. A therapeutic neck dissection is mandatory when clinically positive lymph node metastases are present [19]. In some cases, adjuvant radiotherapy (RT) or chemoradiation therapy 
is recommended after surgery with malignant tumors [19,59]. Radiotherapy however may cause salivary gland hypofunction and xerostomia which will impair the patient's qulaity of life [73]. In cases where occasional, conservative management is chosen of an incidental solid salivary mass, US follow-up is mandatory, with repeated US guided FNAC when suspicious ultrasound features or when rapid growth are observed.

\section{Clinical scenarios and role of ultrasound}

\section{Detection of SI by ultrasound}

The inclusion of salivary gland screening in the protocol of US examinations of other head and neck structures depends on the available time, national regulations and meticulous examination of the sonologist. In case of detection of a SI by US, the next step is to suggest US-FNAC/FNAB and US follow up, depending on the cytopathology result, as well as a consultation by an otorhinolaryngology specialist.

\section{Ethical issues, psychological burden}

The general public are generally less aware of the spectrum of salivary glands diseases in comparison with pathologies of other human organs. They usually do not connect salivary glands with cancer or other neoplastic diseases, as they do in case of breast, prostate, lungs, liver or brain. Some are even not conscious of having such glands.

Therefore, SIs suggested for control imaging or FNAB usually do not concern people very much.

\section{Informed decision making}

When a SI FNAC result suggests primary salivary malignancy, there are usually no reasons from the patient to refuse surgery, however that may depend on life expectancy. If a detected mass is relatively small and FNAC results are benign, US follow-up should be recommended after informing the patient about possible false negative cytology result and low, but potential risk of malignant transformation. The increased risk of postoperative complications when operating on a larger neoplasm detected later, should also be discussed.

\section{Economic factors}

US suggested for follow up or FNAB verification of a SI is relatively cheap. FNAB in superficial organs usually has no complications or only minor ones. Therefore, the costs of observing or verifying an SI are relatively low, especially taking into consideration the low prevalence of SIs. However, when malignancy is suggested by FNAB, further imaging of a SI is needed: CT or MRI. Nevertheless, early detection leads to treatment at an earlier stage, which is probably more cost-effective as well for the individual patient, as for the medical system.
Acknoweldgement: The authors acknowledge excellent advice from Professor Anil Ahuja

Conflict of interest: none

\section{References}

1. Dietrich CF, Westerway S, Nolsoe C, Kim S, Jenssen C. Commentary on the World Federation for Ultrasound in Medicine and Biology Project "Incidental Findings". Ultrasound Med Biol 2020;46:1815-1820.

2. Dietrich CF, Correas JM, Dong Y, Nolsoe C, Westerway SC, Jenssen C. WFUMB position paper on the management incidental findings: adrenal incidentaloma. Ultrasonography 2020;39:11-21.

3. Bialek EJ, Jakubowski W, Zajkowski P, Szopinski KT, Osmolski A. US of the major salivary glands: anatomy and spatial relationships, pathologic conditions, and pitfalls. Radiographics 2006;26:745-763.

4. El-Naggar AK CJ, Grandis JR, Takata T, Slootweg PJ. World Health Organization classification of tumours: pathology and genetics of head and neck tumours. 4th ed. In: International Agency for Research on Cancer (IARC); 2017; Lyon; 2017.

5. Bradley PJ. Frequency and Histopathology by Site, Major Pathologies, Symptoms and Signs of Salivary Gland Neoplasms. Adv Otorhinolaryngol 2016;78:9-16.

6. Bradley PJ, McGurk M. Incidence of salivary gland neoplasms in a defined UK population. Br J Oral Maxillofac Surg 2013;51:399-403.

7. Rajendran A SB. Shafer's Textbook of Oral Pathology. 7th ed. Elsevier Health Sciences 2014.

8. Dispenza F, Cicero G, Mortellaro G, Marchese D, Kulamarva G, Dispenza C. Primary non-Hodgkins lymphoma of the parotid gland. Braz J Otorhinolaryngol 2011;77:639-644.

9. Seifert G, Hennings K, Caselitz J. Metastatic tumors to the parotid and submandibular glands--analysis and differential diagnosis of 108 cases. Pathol Res Pract 1986;181:684-692.

10. Bron LP, Traynor SJ, McNeil EB, O’Brien CJ. Primary and metastatic cancer of the parotid: comparison of clinical behavior in 232 cases. Laryngoscope 2003;113:1070-1075.

11. Franzen A, Buchali A, Lieder A. The rising incidence of parotid metastases: our experience from four decades of parotid gland surgery. Acta Otorhinolaryngol Ital 2017;37:264-269.

12. Li LJ, Li Y, Wen YM, Liu H, Zhao HW. Clinical analysis of salivary gland tumor cases in West China in past 50 years. Oral Oncol 2008;44:187-192.

13. Stryjewska-Makuch G, Kolebacz B, Janik MA, Wolnik A. Increase in the incidence of parotid gland tumors in the years 2005-2014. Otolaryngol Pol 2017;71:29-34.

14. Tian Z, Li L, Wang L, Hu Y, Li J. Salivary gland neoplasms in oral and maxillofacial regions: a 23 -year retrospective study of 6982 cases in an eastern Chinese population. Int J Oral Maxillofac Surg 2010;39:235-242.

15. RA Willis. Epithelial tumors of the salivary glands. In: Pathology of Tumors, 2nd ed. Butterworth, London; 1953:320-348. 
16. Spiro RH. Salivary neoplasms: overview of a 35-year experience with 2,807 patients. Head Neck Surg 1986;8:177-184.

17. Bello IO, Salo T, Dayan D, et al. Epithelial salivary gland tumors in two distant geographical locations, Finland (Helsinki and Oulu) and Israel (Tel Aviv): a 10-year retrospective comparative study of 2,218 cases. Head Neck Pathol 2012;6:224-231.

18. Boukheris H, Curtis RE, Land CE, Dores GM. Incidence of carcinoma of the major salivary glands according to the WHO classification, 1992 to 2006: a population-based study in the United States. Cancer Epidemiol Biomarkers Prev 2009;18:2899-2906.

19. Mantravadi AV, Moore MG, Rassekh CH. AHNS series: Do you know your guidelines? Diagnosis and management of salivary gland tumors. Head Neck 2019;41:269-280.

20. Kanesa-Thasan R, Cox M, Patel M, et al. Actionable vascular and other incidental findings on CTA in patients undergoing acute stroke intervention. Neuroradiol J 2018;31:572577.

21. Sandeman EM, Hernandez Mdel C, Morris Z, et al. Incidental findings on brain MR imaging in older communitydwelling subjects are common but serious medical consequences are rare: a cohort study. PLoS One 2013;8:e71467.

22. Makdissi J, Pawar RR, Radon M, Holmes SB. Incidental findings on MRI of the temporomandibular joint. Dentomaxillofac Radiol 2013;42:20130175.

23. Barbara RR, Pawaroo D, Beadsmoore C, Hujairi N, Newman D. Parotid incidentalomas on positron emission tomography: what is their clinical significance? Nucl Med Commun 2019;40:264-269.

24. Makis W, Ciarallo A, Gotra A. Clinical significance of parotid gland incidentalomas on (18)F-FDG PET/CT. Clin Imaging 2015;39:667-671.

25. Ustun F, Tastekin E, Tas A, Altun GD. The Clinical Significance of Incidental Parotid Uptake in a PET/CT Study: A Diagnostic Algorithm. Curr Med Imaging Rev 2019;15:326-333.

26. Treglia G, Bertagna F, Sadeghi R, Muoio B, Giovanella L. Prevalence and risk of malignancy of focal incidental uptake detected by fluorine-18-fluorodeoxyglucose positron emission tomography in the parotid gland: a meta-analysis. Eur Arch Otorhinolaryngol 2015;272:3617-3626.

27. Mabray MC, Behr SC, Naeger DM, Flavell RR, Glastonbury CM. Predictors of pathologic outcome of focal FDG uptake in the parotid gland identified on whole-body FDG PET imaging. Clin Imaging 2015;39:1073-1079.

28. Britt CJ, Stein AP, Patel PN, Harari PM, Hartig GK. Incidental Parotid Neoplasms: Pathology and Prevalence. Otolaryngol Head Neck Surg 2015;153:566-568.

29. O'Sullivan JW, Muntinga T, Grigg S, Ioannidis JPA. Prevalence and outcomes of incidental imaging findings: umbrella review. BMJ 2018;361:k2387.

30. Haldar S, Sinnott JD, Tekeli KM, Turner SS, Howlett DC. Biopsy of parotid masses: Review of current techniques. World J Radiol 2016;8:501-505.

31. Lanisnik B, Levart P, Cizmarevic B, Svagan M. Surgeonperformed ultrasound with fine-needle aspiration biopsy for the diagnosis of parotid gland tumors. Head Neck 2021. doi:10.1002/hed.26630.

32. Onda K, Fukuhara T, Matsuda E, et al. Impact of Screening for Salivary Gland by Ultrasonography. Yonago Acta Med 2020;63:42-46.

33. Sigismund PE, Zenk J, Koch M, Schapher M, Rudes M, Iro H. Nearly 3,000 salivary stones: some clinical and epidemiologic aspects. Laryngoscope 2015;125:1879-1882.

34. Buch K, Nadgir RN, Fujita A, Tannenbaum AD, Ozonoff A, Sakai O. Clinical associations of incidentally detected parotid gland calcification on CT. Laryngoscope 2015;125:1360-1365.

35. Togan B, Gander T, Lanzer M, Martin R, Lubbers HT. Incidence and frequency of nondental incidental findings on cone-beam computed tomography. J Craniomaxillofac Surg 2016;44:1373-1380.

36. Pace C, Ward S. Incidental finding of sialolithiasis in the sublingual gland: a diagnostic dilemma. Dent Update 2011;38:704-705.

37. Lin HH, Limesand KH, Ann DK. Current State of Knowledge on Salivary Gland Cancers. Crit Rev Oncog 2018;23:139-151.

38. Gallo O, Franchi A. Aetiology and molecular changes in salivary gland tumours. In: McGurk M, Combes J. (Eds.). Controversies in the Management of Salivary Gland Disease. 2nd Edition. Oxford University Press; Oxford, 2012.

39. Matse JH, Yoshizawa J, Wang X, et al. Human Salivary Micro-RNA in Patients with Parotid Salivary Gland Neoplasms. PLoS One 2015; 10:e0142264.

40. Valstar MH, de Ridder M, van den Broek EC, et al. Salivary gland pleomorphic adenoma in the Netherlands: A nationwide observational study of primary tumor incidence, malignant transformation, recurrence, and risk factors for recurrence. Oral Oncol 2017;66:93-99.

41. Andreasen S, Therkildsen MH, Bjorndal K, Homoe P. Pleomorphic adenoma of the parotid gland 1985-2010: A Danish nationwide study of incidence, recurrence rate, and malignant transformation. Head Neck 2016;38 Suppl 1:E1364-E1369.

42. Seifert G. Carcinoma in pre-existing Warthin tumors (cystadenolymphoma) of the parotid gland. Classification, pathogenesis and differential diagnosis. Pathologe 1997;18:359-367.

43. Alnoor FNU, Gandhi JS, Stein MK, Solares J, Gradowski JF. Prevalence of Lymphoid Neoplasia in a Retrospective Analysis of Warthin Tumor: A Single Institution Experience. Head Neck Pathol 2020;14:944-950.

44. Elmokadem AH, Abdel Khalek AM, Abdel Wahab RM, et al. Diagnostic Accuracy of Multiparametric Magnetic Resonance Imaging for Differentiation Between Parotid Neoplasms. Can Assoc Radiol J 2019;70:264-272.

45. Borsetto D, Fussey JM, Cazzador D, et al. The diagnostic value of cytology in parotid Warthin's tumors: international multicenter series. Head Neck 2020;42:522-529.

46. Bialek EJ, Jakubowski W, Karpinska G. Role of ultrasonography in diagnosis and differentiation of pleomorphic 
adenomas: work in progress. Arch Otolaryngol Head Neck Surg 2003;129:929-933.

47. Rousseau A, Badoual C. Head, neck: Salivary gland tumors: an overview. Atlas Genet Cytogenet Oncol Haematol 2011;15:533-541.

48. Shimizu M, Ussmuller J, Hartwein J, Donath K, Kinukawa N. Statistical study for sonographic differential diagnosis of tumorous lesions in the parotid gland. Oral Surg Oral Med Oral Pathol Oral Radiol Endod 1999;88:226-233.

49. Pantanowitz L, Thompson LDR, Rossi ED. Diagnostic Approach to Fine Needle Aspirations of Cystic Lesions of the Salivary Gland. Head Neck Pathol 2018;12:548-561.

50. David E, Cantisani V, De Vincentiis M, et al. Contrast-enhanced ultrasound in the evaluation of parotid gland lesions: an update of the literature. Ultrasound 2016;24:104-110.

51. Bhatia KS, Lee YY, Yuen EH, Ahuja AT. Ultrasound elastography in the head and neck. Part II. Accuracy for malignancy. Cancer Imaging 2013;13:260-276.

52. Zhang YF, Li H, Wang XM, Cai YF. Sonoelastography for differential diagnosis between malignant and benign parotid lesions: a meta-analysis. Eur Radiol 2019;29:725-735.

53. Badarinza M, Serban O, Maghear L, et al. Shear wave elastography as a new method to identify parotid lymphoma in primary Sjogren Syndrome patients: an observational study. Rheumatol Int 2020;40:1275-1281.

54. Jiang JS, Zhu LN, Chen W, et al. Added value of susceptibility-weighted imaging to diffusion-weighted imaging in the characterization of parotid gland tumors. Eur Arch Otorhinolaryngol 2020;277:2839-2846.

55. Pietragalla M, Nardi C, Bonasera L, et al. The role of diffusion-weighted and dynamic contrast enhancement perfusion-weighted imaging in the evaluation of salivary glands neoplasms. Radiol Med 2020;125:851-863.

56. Bae YJ, Choi BS, Jeong WJ, et al. Amide Proton Transferweighted MRI in the Diagnosis of Major Salivary Gland Tumors. Sci Rep 2019;9:8349.

57. Kikuchi M, Koyasu S, Shinohara S, Imai Y, Hino M, Naito Y. Preoperative Diagnostic Strategy for Parotid Gland Tumors Using Diffusion-Weighted MRI and Technetium-99m Pertechnetate Scintigraphy: A Prospective Study. PLoS One 2016;11:e 0148973.

58. Nakahara T, Suzuki T, Hashimoto J, et al. Role of salivary gland scintigraphy with Tc-99m pertechnetate in determining treatment of solitary parotid gland tumors: a retrospective study. Clin Nucl Med 2007;32:363-366.

59. Sood S, McGurk M, Vaz F. Management of Salivary Gland Tumours: United Kingdom National Multidisciplinary Guidelines. J Laryngol Otol 2016;130:S142-S149.

60. Wierzbicka M, Napierala J. Updated National Comprehensive Cancer Network guidelines for treatment of head and neck cancers 2010-2017. Otolaryngol Pol 2017;71:1-6.
61. Liu CC, Jethwa AR, Khariwala SS, Johnson J, Shin JJ. Sensitivity, Specificity, and Posttest Probability of Parotid Fine-Needle Aspiration: A Systematic Review and Metaanalysis. Otolaryngol Head Neck Surg 2016;154:9-23.

62. Zbaren P, Triantafyllou A, Devaney KO, et al. Preoperative diagnostic of parotid gland neoplasms: fine-needle aspiration cytology or core needle biopsy? Eur Arch Otorhinolaryngol 2018;275:2609-2613.

63. Feinstein AJ, Alonso J, Yang SE, St John M. Diagnostic Accuracy of Fine-Needle Aspiration for Parotid and Submandibular Gland Lesions. Otolaryngol Head Neck Surg 2016;155:431-436.

64. Song IH, Song JS, Sung CO, et al. Accuracy of Core Needle Biopsy Versus Fine Needle Aspiration Cytology for Diagnosing Salivary Gland Tumors. J Pathol Transl Med 2015;49:136-143.

65. Galli A, Tulli M, Giordano L, et al. Fine needle aspiration cytology for parotid neoplasms: risk of malignancy through inconclusive results and lower grade tumors. Eur Arch Otorhinolaryngol 2020;277:841-851.

66. Suzuki M, Kawata R, Higashino M, et al. Values of fineneedle aspiration cytology of parotid gland tumors: A review of 996 cases at a single institution. Head Neck 2019;41:358-365.

67. Eytan DF, Yin LX, Maleki Z, et al. Utility of preoperative fine needle aspiration in parotid lesions. Laryngoscope 2018;128:398-402.

68. Del Cura JL, Coronado G, Zabala R, Korta I, Lopez I. Accuracy and effectiveness of ultrasound-guided core-needle biopsy in the diagnosis of focal lesions in the salivary glands. Eur Radiol 2018;28:2934-2941.

69. Baer AN, Grader-Beck T, Antiochos B, Birnbaum J, Fradin JM. Ultrasound-guided biopsy of suspected salivary gland lymphoma in Sjogren's syndrome. Arthritis Care Res (Hoboken) 2020. doi:10.1002/acr.24203.

70. Romano EB, Wagner JM, Alleman AM, Zhao L, Conrad RD, Krempl GA. Fine-needle aspiration with selective use of core needle biopsy of major salivary gland tumors. Laryngoscope 2017;127:2522-2527.

71. Cabecadas J, Martinez D, Andreasen S, et al. Lymphomas of the head and neck region: an update. Virchows Arch 2019;474:649-665.

72. Li C, Matthies L, Hou X, Knipfer C, Gosau M, Friedrich RE. A meta-analysis of the pros and cons of partial superficial parotidectomy versus superficial parotidectomy for the treatment of benign parotid neoplasms. J Craniomaxillofac Surg 2020;48:590-598.

73. Jensen SB, Vissink A, Limesand KH, Reyland ME. Salivary Gland Hypofunction and Xerostomia in Head and Neck Radiation Patients. J Natl Cancer Inst Monogr 2019;2019:/gz016. 